Nordic Concrete Research - Publ. No. NCR 60 - ISSUE 1 / 2019 - Article 6, pp. 89-104

\begin{tabular}{|l|r|}
\hline \multicolumn{1}{|c|}{ S sciendo } & $\begin{array}{c}\text { Nordic } \\
\text { Concrete } \\
\text { Federation }\end{array}$ \\
\hline $\begin{array}{l}\text { C Article authors. This is an open access article distributed under } \\
\text { the Creative Commons Attribution-NonCommercial-NoDerivs } \\
\text { licens. (http://creaticecommons.org/licenses/by.nc-nd/3.0/). }\end{array}$ & $\begin{array}{l}\text { ISSN online 2545-2819 } \\
\text { ISSN print } 0800-6377\end{array}$ \\
\hline DOI: $10.2478 /$ ncr-2019-0001 & $\begin{array}{r}\text { Received: January 22, 2019 } \\
\text { Revision received: June 26, 2019 } \\
\text { Accepted: June 26, 2019 }\end{array}$ \\
\hline
\end{tabular}

\title{
Cracking of the End Diaphragm of a Post-tensioned Beam Bridge
}

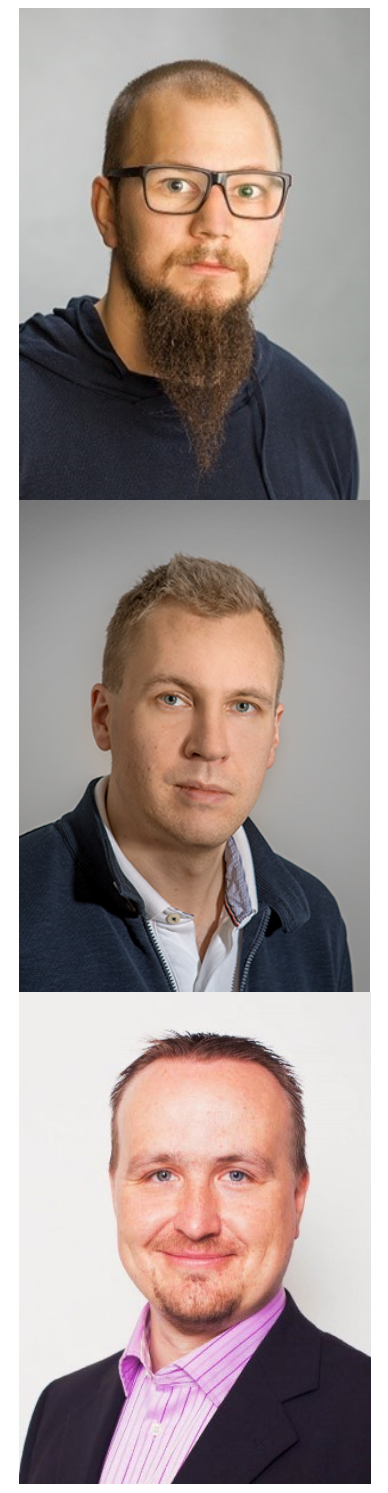

\author{
Mikko Kuusela, MSc. \\ Bridge Engineer, A-Insinöörit Civil Oy, Tampere, Finland \\ mikko.kuusela@ains.fi
}

Olli Asp, MSc.

Research Scientist, Tampere University, Tampere, Finland olli.asp@tuni.fi

\begin{abstract}
Anssi Laaksonen, PhD.
Professor, Tampere University, Tampere, Finland

anssi.laaksonen@tuni.fi
\end{abstract}

\begin{abstract}
In concrete beam bridges, the end diaphragm at the end of the bridge is a common structural component that connects the main beams and transfers the beam loads to the bridge bearings. In integral bridges the end diaphragm also retains the soil of embankments due to the absence of abutments. Cracking of the front surface on the end diaphragm has been detected in post-tensioned
\end{abstract}


beam bridges in Finland and Sweden. Presumably the post-tensioning of the bridge and the shaping and detailing of the connection of the end diaphragm and main beam have an effect on cracking tendency. The aim of this study is to examine the structural behaviour and the cracking potential of end diaphragms using linear analysis of the post-tensioned bridge and to find measures to prevent the cracking.

The observations collected through field surveys are compared to results of linear FE analysis to clarify the cause of the cracking. The verification of model is performed by comparison of patterns of cracking observed in field surveys and the distribution of maximum tensile stresses in the FE model. With model variations, the effectiveness of measures for the prevention of cracking are observed.

Key words: Bridge, post-tensioning, end diaphragm, concrete, cracking.

1.

\section{INTRODUCTION AND BACKGROUND}

It has been detected that cracking after post-tensioning occurs in the front surface on the end diaphragm of beam bridges. This problem has been detected in Finland and Sweden $[1,2]$. Posttensioned beam bridges are very common bridge structures in Finland. For example, in 2015 some $23 \%$ of all bridges built were post-tensioned beam bridges [3].

The aim of this study was to find out the causes of the cracking and ways to prevent it. The causes of cracking were examined using FEM analysis. The main purpose was to examine the structure rather than to improve modelling. In addition, this study examines what kind of cracking typically appears on the end diaphragm of post-tensioned bridges (described in the Field Surveys section). At Chalmers University of Technology (Sweden), a master's thesis on the same subject was written using nonlinear FE analysis. In the thesis, it was found that cracking only occurs due to prestressing force and vertical loads do not have an effect on cracking. According to the thesis, the most efficient way to limit the cracks is to insert more horizontal reinforcement on the front surface of the end diaphragm [1].

\subsection{Field Surveys}

The field surveys were performed on 16 bridges. The cracking of the end diaphragms was detected on inspections of these bridges. The surveys included several types of post-tensioned bridges. However, the end diaphragms were basically the same type, connected directly to the main girder by an indirect support, which means the main beam of the bridge is connected on the side of the supporting end diaphragm. The number of main girders varied between one and three. The height of the end diaphragm and the main girder varied between 1.3 and 2.3 metres and the width of the web varied from 1.2 to 5.4 metres.

Three of the examined bridges are continuous and with a short cantilever (overhang), while the others are supported from the ends with piles or bearings. The end spans vary between 16.5 and 42.5 metres. The amount of horizontal reinforcement in the front surface of the end diaphragm varies between $1005 \mathrm{~mm}^{2} / \mathrm{m}$ and $4909 \mathrm{~mm}^{2} / \mathrm{m}$. General information about the observed bridges is presented in the annexes in Table 1. 
The surveys show that there are typically two kinds of cracking caused by post-tensioning. The first type of crack is inclined cracks between the main girder and the bearing (showed in Figure 1a). The second type is vertical cracks following the connection to the main girder web (showed in Figure 1b). The cracking below the flanges is also noted. On integral bridges with a higher end diaphragm, the cracking also occurs below the wedge of the girder (showed in Figure 1c).

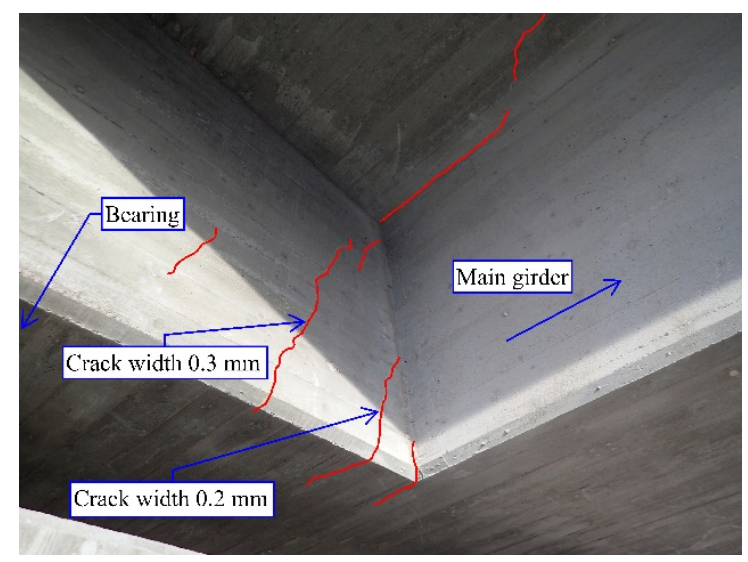

(a)

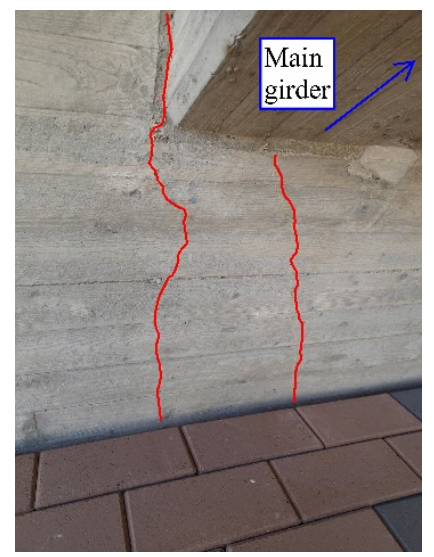

(c)

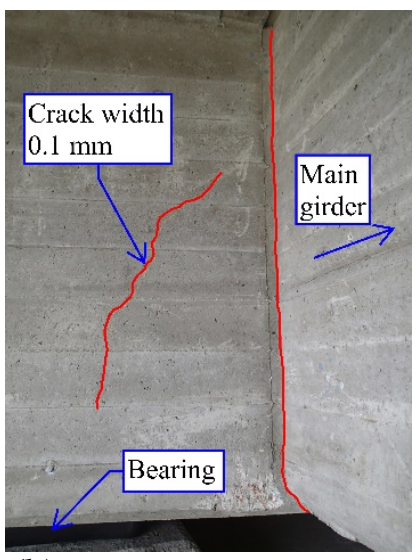

(b)

Figure 1 - Cracking on the front surface of the end diaphragm a) Sähköaseman risteyssilta (first case bridge), b) Skågbyntien risteyssilta (second case bridge), c) Pyhtään risteyssilta

The measured crack width varies between $0.1 \ldots 0.5 \mathrm{~mm}$. Cracking seems to be a common problem. For example, the cracking is detected on eight out of a total of 24 post-tensioned bridges in the E18 Koskenkylä-Kotka project. This type of behaviour is also discovered at the end diaphragms of bridges in other projects: Tampereen Rantatunneli, Kehä III VT4-VT7 and Kehä III Lentoasemantie [2].

\section{Case Bridges}

Finite-element analysis included two flyover bridges: Sähköaseman risteyssilta (Vantaa) and Skågbyntien risteysssilta (Loviisa). FE analysis was limited to bridges which have one main girder and bearings on the end support. The observed cracking was similar in the bridges of the same type. The first of the case bridges was chosen for the analysis because its prestressing force is 
high, which requires a lot of post-tensioning anchors. A significant amount of cracking on the front surface of the end diaphragm is observed.

The second case bridge was chosen because it has almost the same dimensions on the end diaphragm as the first case bridge, but much less prestressing force. The bearings are located closer to each other than in the first case bridge. The second case bridge is also an integral bridge while the first one is not. The case bridges represent typical Finnish post-tensioned beam bridges. The crack pattern and geometry of the case bridges are shown in Figures 2 and 3.
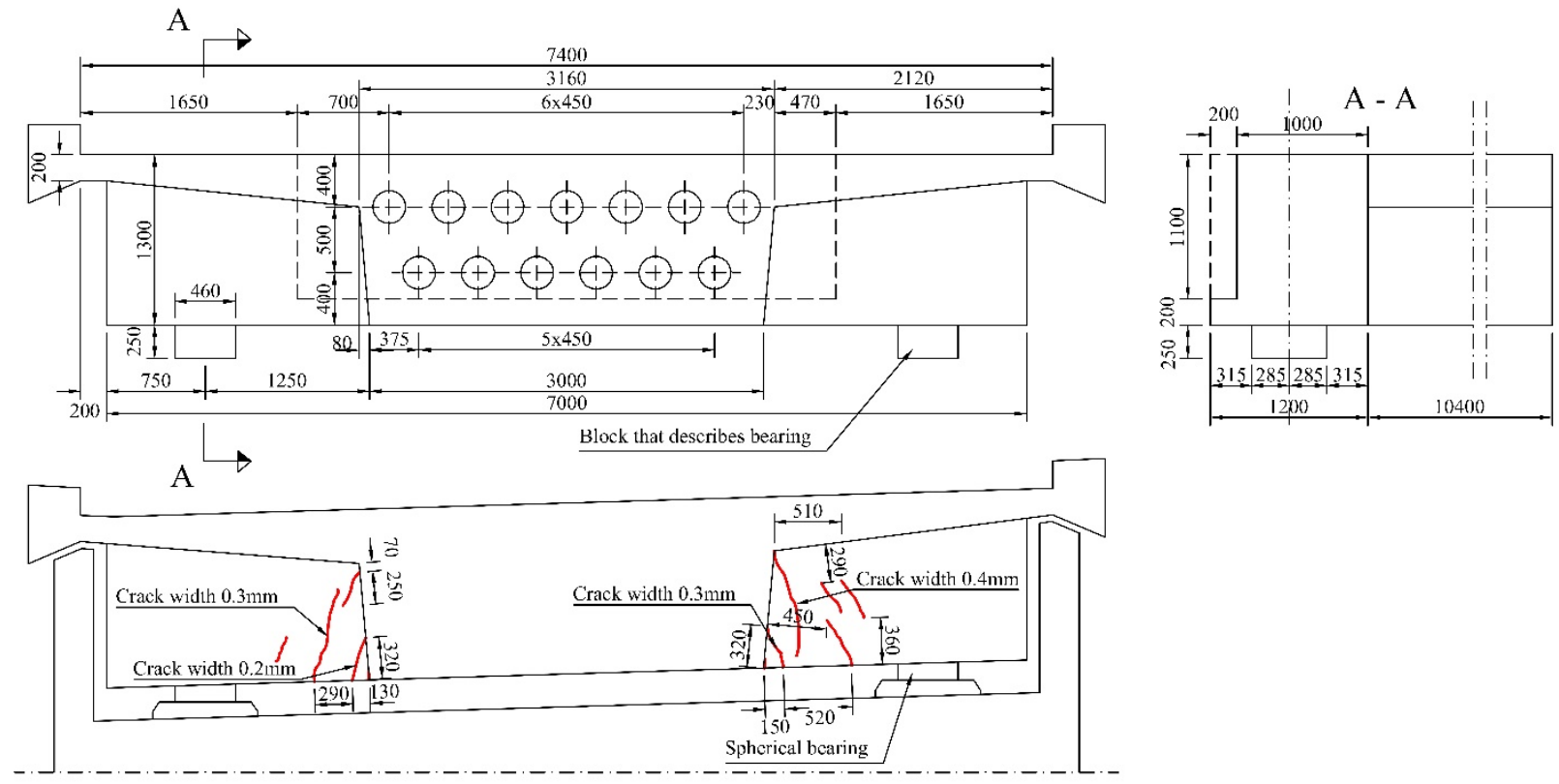

Figure 2 - Geometry of the volume model (upper) and the crack pattern of the first case bridge (lower), span length 28.2+47.0+28.2 m
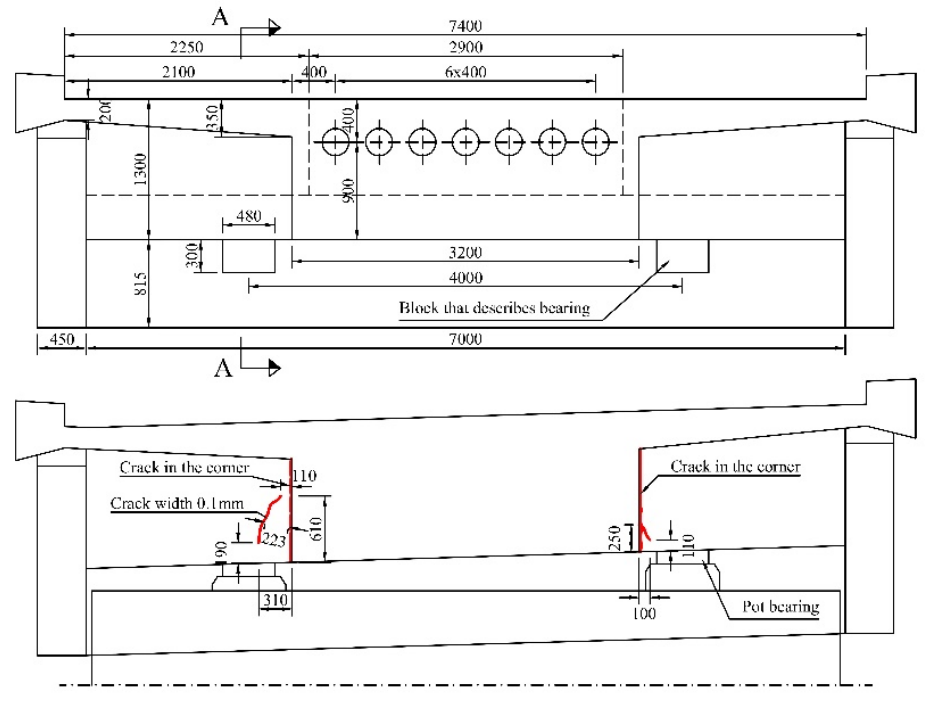

Figure 3 - Geometry of the volume model (upper) and the crack pattern of the second case bridge (lower), span length $26.0+26.0 \mathrm{~m}$

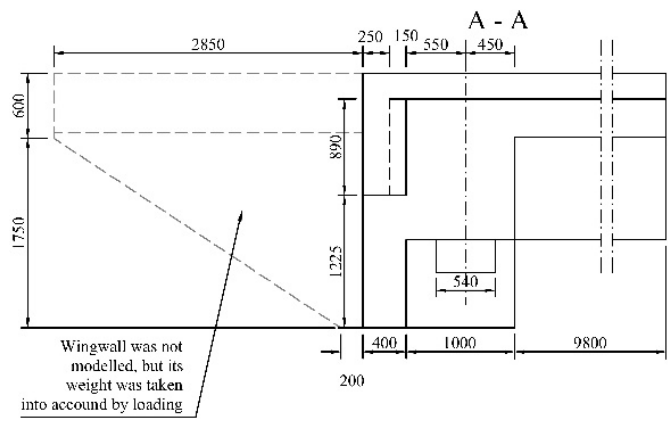


FE analysis is performed by using solid elements and linear calculations. The cracking studied is located in a discontinuity area and therefore it is a three-dimensional problem. That is why the slab or shell elements were not suitable for analysis. A cross section of the volumetric model included only concrete and reinforcement was not considered. The study is performed by examining tensile stresses and comparing them to concrete tensile strength. The use of non-linear analysis with various parameters would have been too time consuming and the verification of results would have been difficult. Using linear modelling is considered to be more reliable.

The material model is linear elastic $\left(E=34 \mathrm{GPa}, \mathrm{v}=0.2, \gamma=25 \mathrm{kN} / \mathrm{m}^{3}\right)$. In the calculation, the cracking is not taken into account, as the calculation is linear. Therefore, during the combination of results the superposition principle can be used. The elements mainly used in modelling are 3D hexagonal solid elements with 20 nodes (HX20 in [4]) and pentagonal solid elements with 15 nodes (PN15 in [4]). Both used elements are with quadratic interpolation order. The size of the mesh was $100 \mathrm{~mm}$ in the area in which the highest tensile stresses are assumed, and $200 \mathrm{~mm}$ in other areas in order to keep the calculation time reasonable. The element size was identified by starting with a coarse mesh and refining it, until the calculation time was approximately 30-45 minutes [2].

Only the end area of the bridge is modelled with solid elements; including the end diaphragm and approximately 11 metres of the main girder. This corresponds to $39 \%$ of the first span of the first case bridge and $42 \%$ of the span of the second case bridge. The main girder is intercepted in a rigid zone, where the rigid nodal support is attached. The bearings are modelled with the same material parameters as the bridge girder and the same size as the bearing plate. Rigid plates are attached under bearing. The stiff beam, with a length of $100 \mathrm{~mm}$, is used to connect the rigid plate to the nodal support under the bearing. The nodal support at the lower end of the stiff beam is fixed in the Z-direction. The friction of the bearing is not included in the analysis. The solid model of the first case bridge is shown in Figure 4a. 

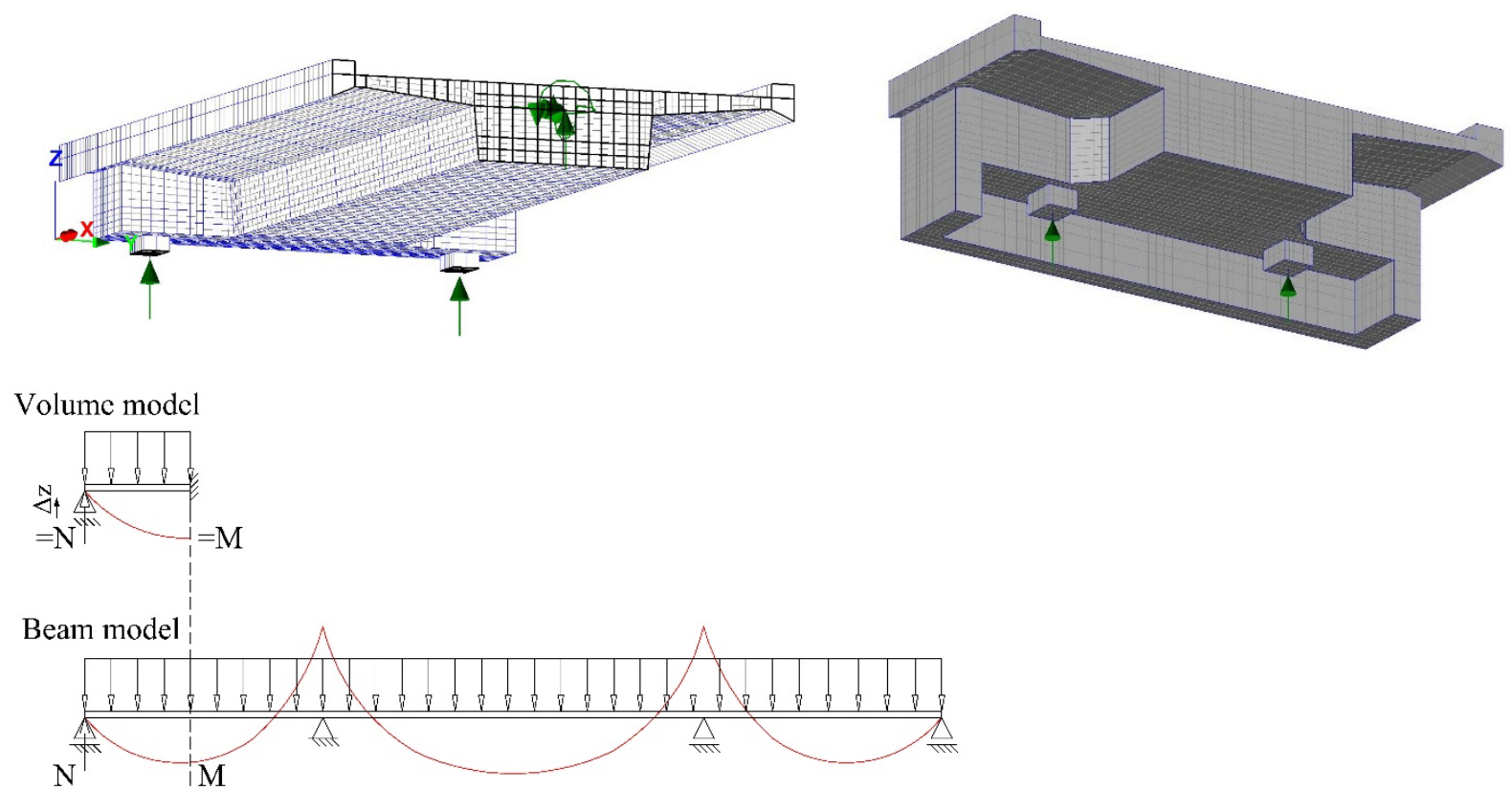

Figure 4 - a) Solid model of the first case bridge b) Solid model of the second case bridge with smaller wedges (the full model is not shown) c) The schematic presentation of the volume model in relation to the beam model

The beam model of the full bridge is used to solve the support reactions of the bearings. Due to loading, the support reactions in the volume model were not as depicted in the beam model at first because it had different support conditions and a different span length to the case bridges. Support reactions in volume model were fitted by modelling additional vertical support displacement, which matches the support reaction to the beam model. The support reactions and forces used are shown in the annexes (Table 2). The beam model is used for comparing bending moments and shear forces to the volume model in order to check the suitability of the solid model.

In the analysis, some simplifications are made. In the model geometry, the longitudinal and horizontal slopes and the inclination, curvature and obliqueness of the end diaphragm, accessories and chamfers are not taken into account. The post-grouting of tendon anchors is neglected because it does not contribute to structural behaviour during post-tensioning. The main girder in the first case bridge is a haunched girder, which is assumed to be constant in height in the volume model. The structure was modelled as symmetrical.

\section{$2.2 \quad$ Loads}

The selection of loads is made based on observations during mould removal, when the cracking end diaphragm is noticed at an early stage. The significant sources of loads effecting new structures are selected.

The loads in the model are the self-weight of structures, post-tension force, traffic load and internal temperature gradient due to hydration of concrete and ambient air temperature fluctuations. The volumetric model is constructed by modelling rigid plates above bearings and pinned supports under plates, and a rigid plate at the location at which the bridge model is cut according to Fig. 4c. The application of loads is performed by using equivalent support 
displacement at bearing locations which the bearing forces with beam model corresponds with. Because the geometry of the model is symmetric and there is no horizontal support on the bearing, all the loads are also modelled symmetrically. Due to this simplification of the model, the torsion of the main girder on the support reaction is not included. Also, the effects caused by asymmetrical traffic (causes torsion) or the effects of asymmetrical temperature gradients are neglected. Because volume models are symmetrical, the stress field has to be symmetrical to verify the model. Influence of creep is not examined. The values of the loads are shown in the annexes (Table 2).

Self-weight included the volumetric weight of the concrete, which was added with gravitation force. The weight of the parapets is included $(0.8 \mathrm{kN} / \mathrm{m})$ with the weight of layers of tarmac $\left(2.64 \mathrm{kN} / \mathrm{m}^{2}\right)$. On the case bridge, two wing walls, which are connected to the bridge and supports, were only modelled by equivalent loading of their self-weight. Earth pressure at rest is modelled on the end screen of the bridge from case 2 . The effect of passive earth pressure is not considered.

Traffic load is modelled by Load Model 1 (EC1991-2, NCCI1). The axle load is $300 \mathrm{kN}$ and one tyre has an effect on a 400x400mm area. It was assumed that a tyre load distributes at an angle of 1:1 in tarmac and it affects the bridge deck over an area of 620x620 $\mathrm{mm}^{2}$. According to the Finnish national annex to Eurocode, the first UDL lane has a load of $9 \mathrm{kN} / \mathrm{m}^{2}$ and the second $6 \mathrm{kN} / \mathrm{m}^{2}$, and outside the lanes $3 \mathrm{kN} / \mathrm{m}^{2}$.

Both bridges have an effective width of 7.5 metres, so a maximum of two lanes fit on the bridge deck. The traffic load is modelled with two combinations. The first combination is single lane loaded in the middle of the bridge deck. The second combination is two lanes loaded central to the bridge deck and for the symmetric loading both of them should have UDL $7.5 \mathrm{kN} / \mathrm{m}^{2}$. It has to be pointed out that the described traffic load attempts to represent the real maximum characteristic loading and it is made for design purposes.

The force used for post-tensioning is post-tension force after immediate losses. The post-tension anchor used in the bridges has three planes that transfer the prestress force to the concrete. Longitudinal post-tension force is modelled on three layers, which were approximately $100 \mathrm{~mm}$ apart from each other. The area on which prestress force affects is simplified to a square, which has the same area as the real anchor $\left(220 \times 220 \mathrm{~mm}^{2}\right)$. The equivalent load on the anchor is modelled on the same area as the horizontal force. The vertical load component of the posttensioning is modelled by an equivalent line load to a line which lies in the middle of the anchor area.

The temperature gradient is only modelled on the web of the girder (shown in Figure 5) for simplification. The hydration temperatures of the end diaphragm and the flanges of the main beam are neglected. The web is the most massive part of the girder and it was assumed to have an effect. In the middle of the girder the temperature difference is $-\Delta \mathrm{T}{ }^{\circ} \mathrm{C}$ (blue) and on the edge $0{ }^{\circ} \mathrm{C}$ (red). The used temperature gradient $\Delta \mathrm{T}$ was $20.0^{\circ} \mathrm{C}$ at the moment of tensioning due to hydration. The modelling temperature gradient is based on measurements of the Myllypuron risteyssilta made by Tampere University of Technology [5] [6]. A creep effect is considered by reducing the temperature gradient by a factor $k=\frac{1}{1+0.85 * \varphi}=\frac{1}{1+0.85 * 0.39}=0.75$. The resulting value on the gradient in model is $15.0^{\circ} \mathrm{C}$. 


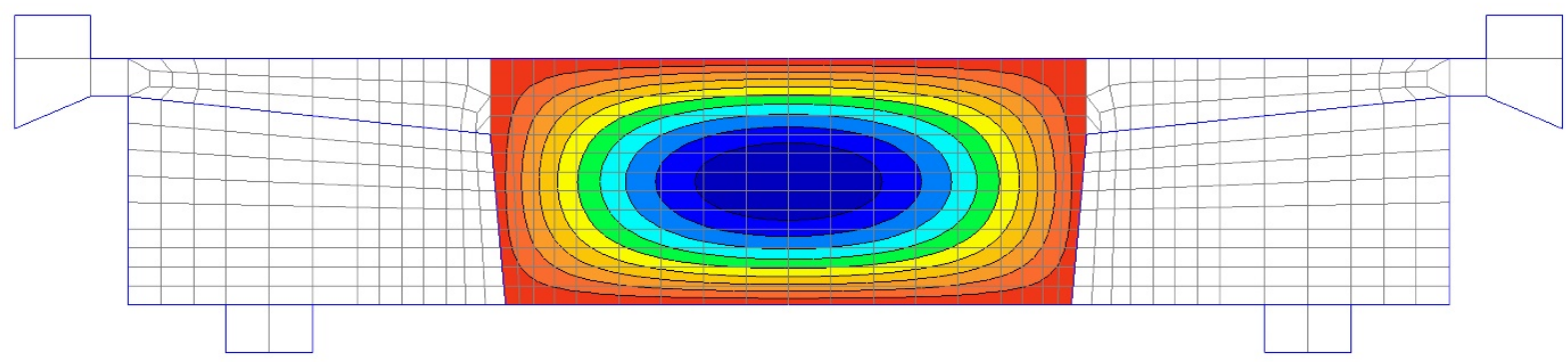

Figure 5 - Modelling of the temperature gradient

The effects of different loads are combined using the superposition principle. All the results were combined with full values.

\subsection{Variations of the structure}

The geometry of the end diaphragm was changed in order to find out how the observed cracking could be reduced. The following variations of structure were studied on the first case bridge:

- the end diaphragm height was extended (downwards) by $400 \mathrm{~mm}$

- $\quad$ the thickness was increased symmetrically by $400 \mathrm{~mm}$ (both sides by $200 \mathrm{~mm}$ )

- the positions of the bearings were each moved $700 \mathrm{~mm}$ closer to the centre of the end diaphragm

On the second case bridge:

- $\quad$ the end diaphragm height was extended (downwards) by $815 \mathrm{~mm}$

- $\quad$ the thickness was raised from the front side by $400 \mathrm{~mm}$ and $800 \mathrm{~mm}$

- $\quad$ setting only one bearing in the middle of the end diaphragm

- two different sizes of wedges $\left(400 \times 400 \mathrm{~mm}^{2}, 640 \times 800 \mathrm{~mm}^{2}\right.$, shape is shown in Figure $\left.4 \mathrm{~b}\right)$.

On both case bridges, the effect of the anchor positioning on the cracking of the diaphragm is examined. The modifications to the model are made one at the time in order to notice the effect of the alteration.

\section{3.}

\section{RESULTS AND ANALYSIS}

As the result of FE analysis, it was found that a crack does not open from a single loading but a combination of them. The magnitude of principal tensile stress is quite the same due to the selfweight, post-tension force, traffic load and temperature gradient of the main girder. Under different types of loads, the stress field is different and the maximum stress is not found at the same point. The schematic stress field at the front surface of the end diaphragm and the location of maximum stresses due to different load cases is shown in Figure 6. 
Nordic Concrete Research - Publ. No. NCR 60 - ISSUE 1 / 2019 - Article 6, pp. 89-104

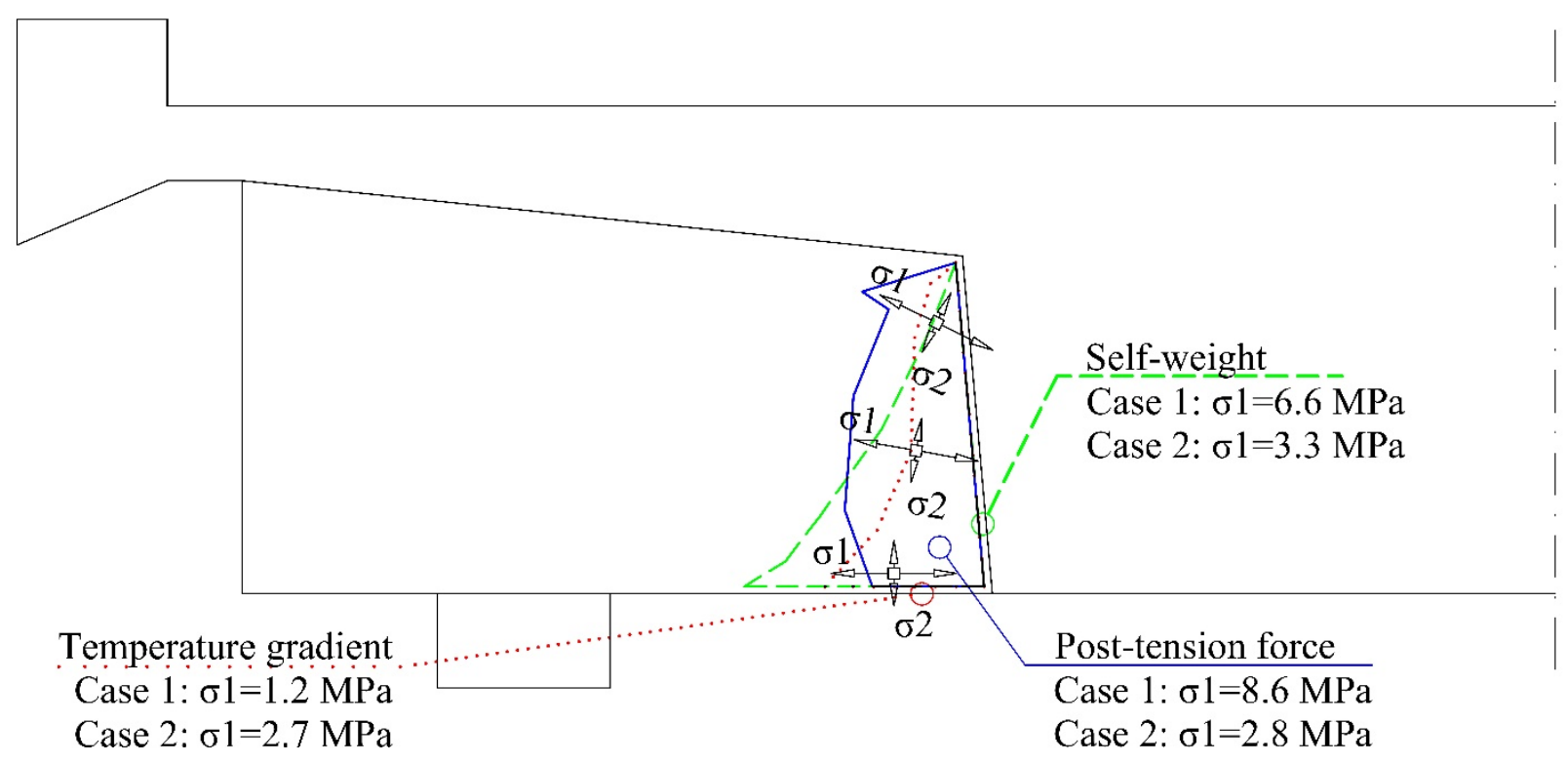

Figure 6-Schematic stress field due to different load cases and maximum tensile stress values with location, corresponding colours and line types in leader(lines) and stress fields

After post-tensioning, the forces added to the structure were self-weight, post-tension force and temperature difference due to hydration temperature. After post-tensioning, the maximum observed principle tensile stress ( $\sigma_{1}$ in Fig. 6) in the model is $10.7 \mathrm{MPa}$ on the first case bridge and $7.6 \mathrm{MPa}$ on the second. This shows that it is most likely that the cracking occurs after posttensioning because a tensile strength $\mathrm{f}_{\text {ctk, } 0.95}$ of the $\mathrm{C} 35 / 45$ concrete is $4.2 \mathrm{MPa}$ [7]. It should also be noted that concrete has not reached its full strength before post-tensioning.

The cracks in concrete are assumed to form in a perpendicular direction to the principal tension stress [8]. In Figure 7 the vectors of principal stresses are shown (blue: compression, red: tension) in the front of the end diaphragm (case 1) after post-tensioning. The perpendicular direction of principal tensile stress matches the observed cracks in the real structure.

In the corner area, the direction of principal tension stresses is almost the same in vertical loads, post-tension force and temperature difference. From the direction of principal stresses, it can be noted that the majority of the tension stress occurs horizontally in the lower part of the end diaphragm. In the upper part of the end diaphragm, the direction inclines and so do the cracks. At the upper part of diaphragm, the horizontal stress component becomes smaller and is not so dominant in comparison to other components. In addition, the highest tensile stresses are detected to be in the same area as the observed cracking in the real structure. 

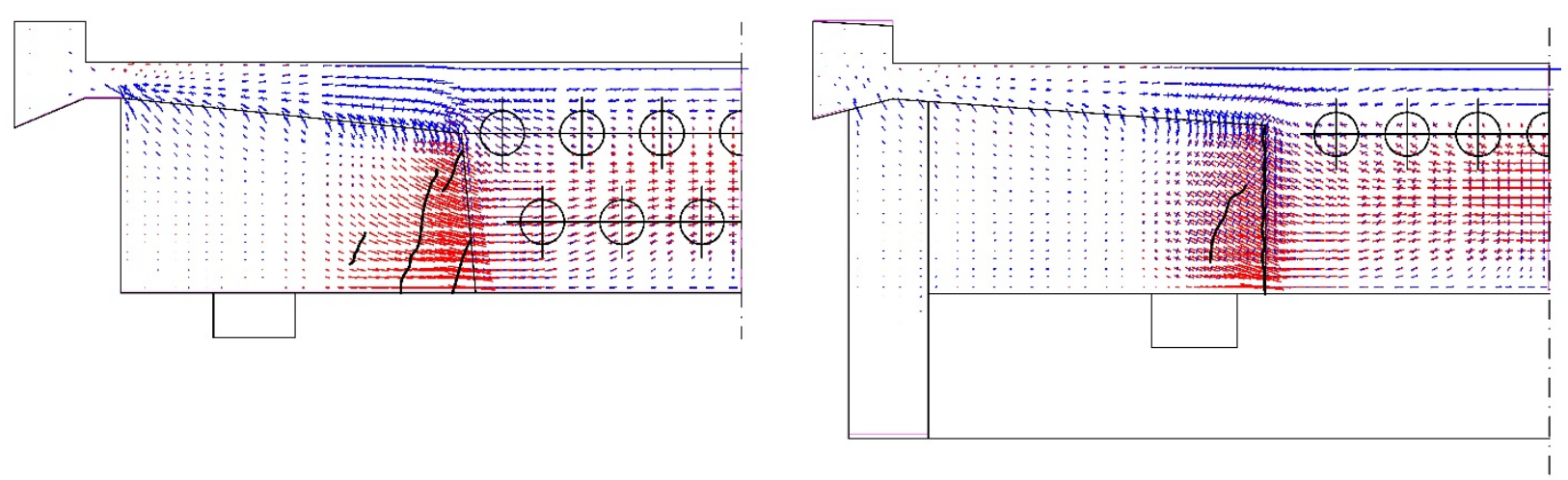

Figure 7 - Direction of cracking compared to principal tensile stress direction left: first case bridge, right: second case bridge)

Because the maximum stresses do not occur at the same location in each load case and do not have same principal direction, they cannot be summed directly. In Figure 8, the principal stresses are shown in the location in which the highest tensile stresses occur after combining all loads. Because the principal stresses are not in same direction, each component is calculated with a weighting so that the resulting stressis correct in the chart. The result is not the same at all points because the contribution of different loads on the total effect is different.

It is significant that making the end diaphragm thicker does not have a great influence on the highest tensile stress. The end diaphragm is not a normal beam loaded with a constant load. Making the end diaphragm thicker also raises the stiffness and consequently the total influence on tensile stress is minor. The highest tensile stresses after post-tensioning on the first case bridge reduced by $11 \%$ by increasing the end diaphragm thickness by $400 \mathrm{~mm}$. On the second case bridge the reduction is $7 \%$. Increasing the thickness of the end diaphragm does not have an influence on the stress pattern and the highest tensile stress gathers in the same area as in the original structure. 
Nordic Concrete Research - Publ. No. NCR 60 - ISSUE 1 / 2019 - Article 6, pp. 89-104

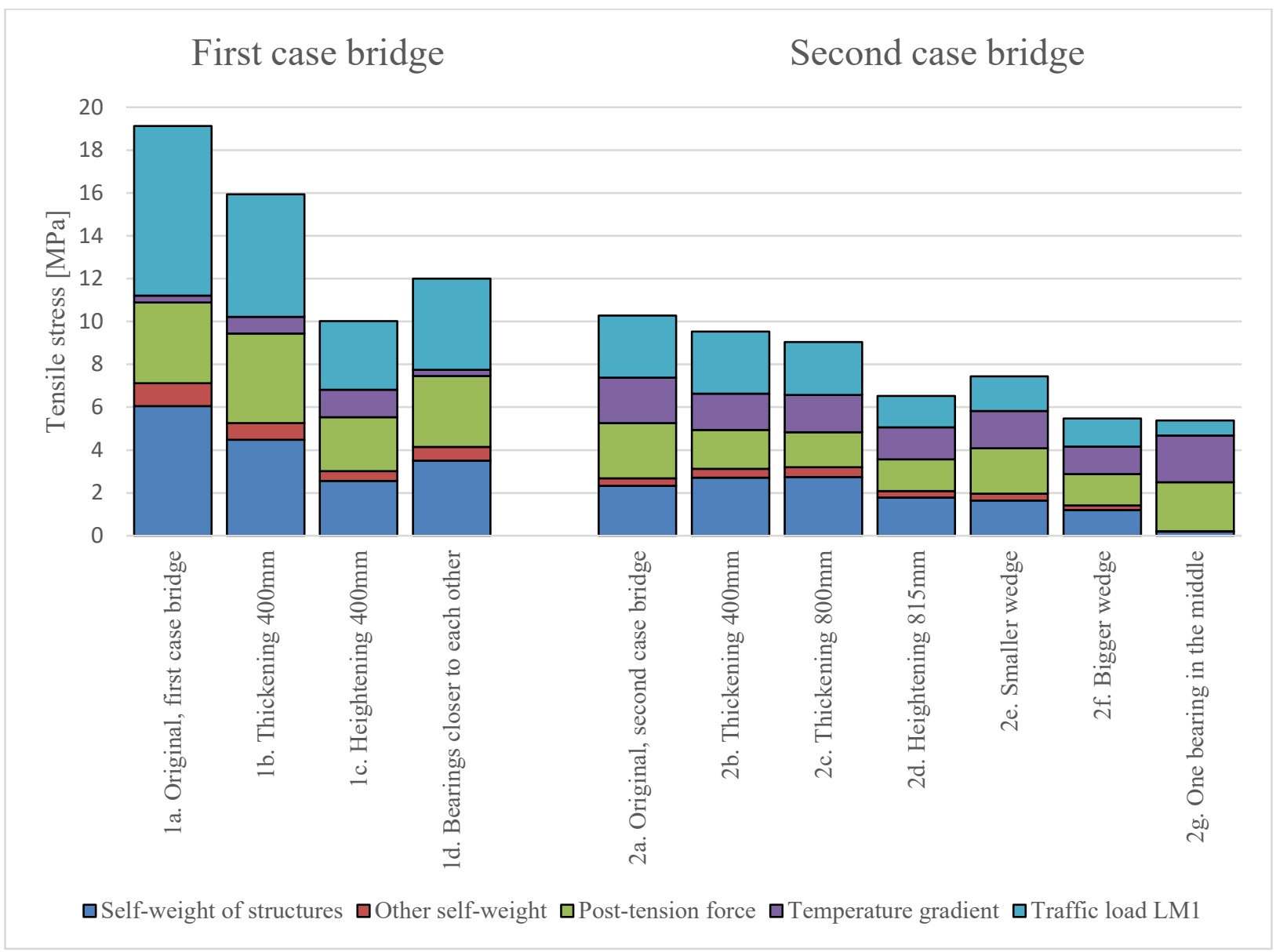

Figure 8 -Combination of stresses on the location with highest total tensile stress

Increasing the height of the end diaphragm has a greater influence on tensile stress than increasing the thickness. It was noted that the stress pattern changed when the end diaphragm was higher. In the original structure the highest stresses occur at the bottom corner of the end diaphragm (shown in Figure 9). In the case with the higher end diaphragm, the highest stresses occur in the upper section in the corner area of the main girder and the end diaphragm. The highest tensile stress was reduced by $38 \%$ on the first case bridge and by $34 \%$ on the second case bridge in the situation after tensioning. 


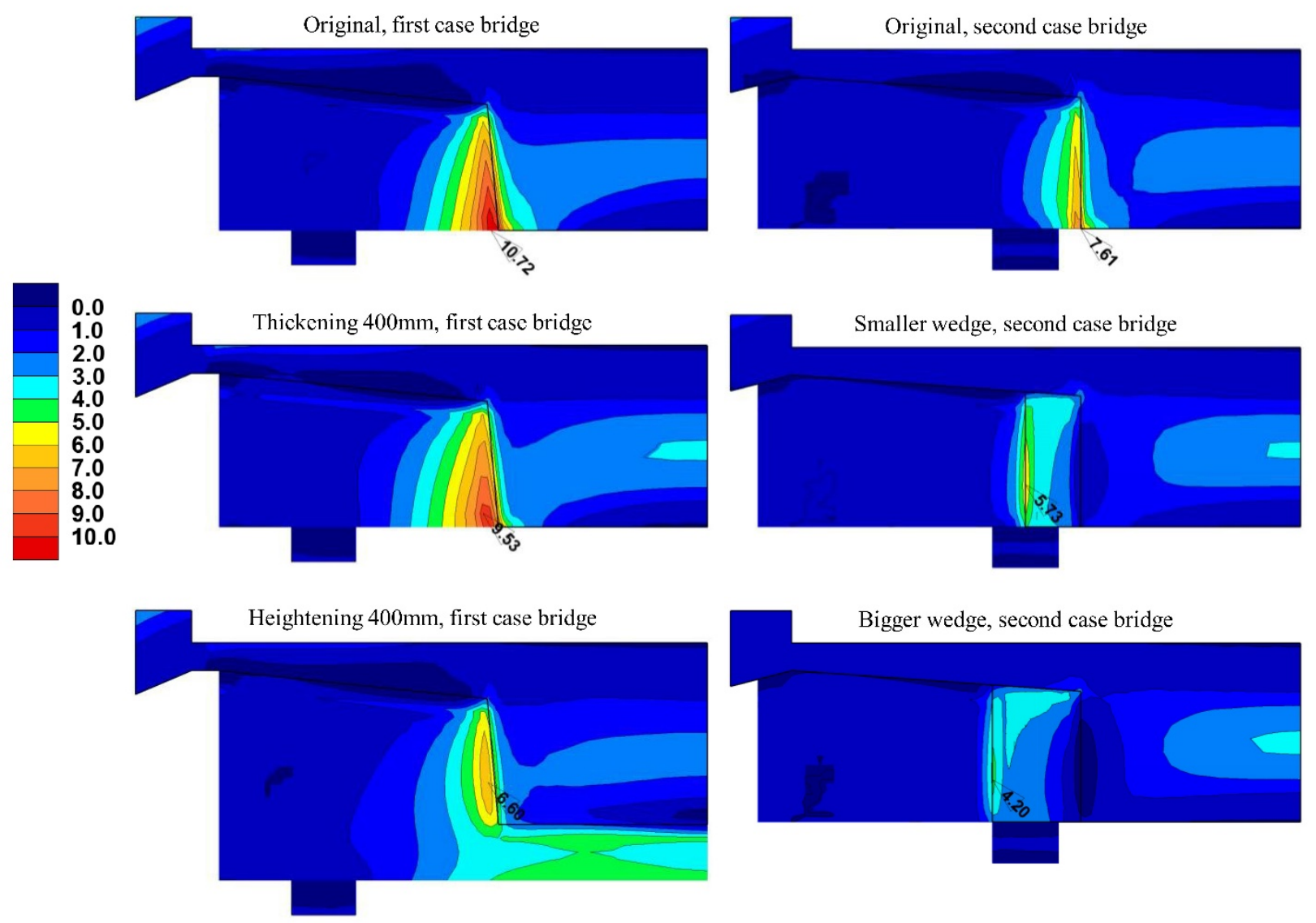

Figure 9-Comparing stress patterns with structure variations

The wedging of the corner reduced the tensile stress significantly (with the smaller wedge by $25 \%$ and the bigger wedge by $45 \%$ after tensioning). Major tensile stresses by prestressing force and horizontal loads occur in different locations on the wedged structure: in the front corner with horizontal loads; and in the back corner with prestressing force. This is why their combination value is not so significant.

In the analysis, it was noted that the position of the post-tension anchors has an effect on the stress values. The upper post-tension anchors cause tension stresses to the entire height of the end diaphragm. The lower anchors cause more tensile stress in the bottom area of the end diaphragm. The schematic tensile stress pattern is shown in Figure 10. Anchors located on the edge of the main girder causes wider tensile stresses in a horizontal direction than those located more closely to the centre of the girder. The anchors on the edge also cause higher tensile stresses than the inner ones. 

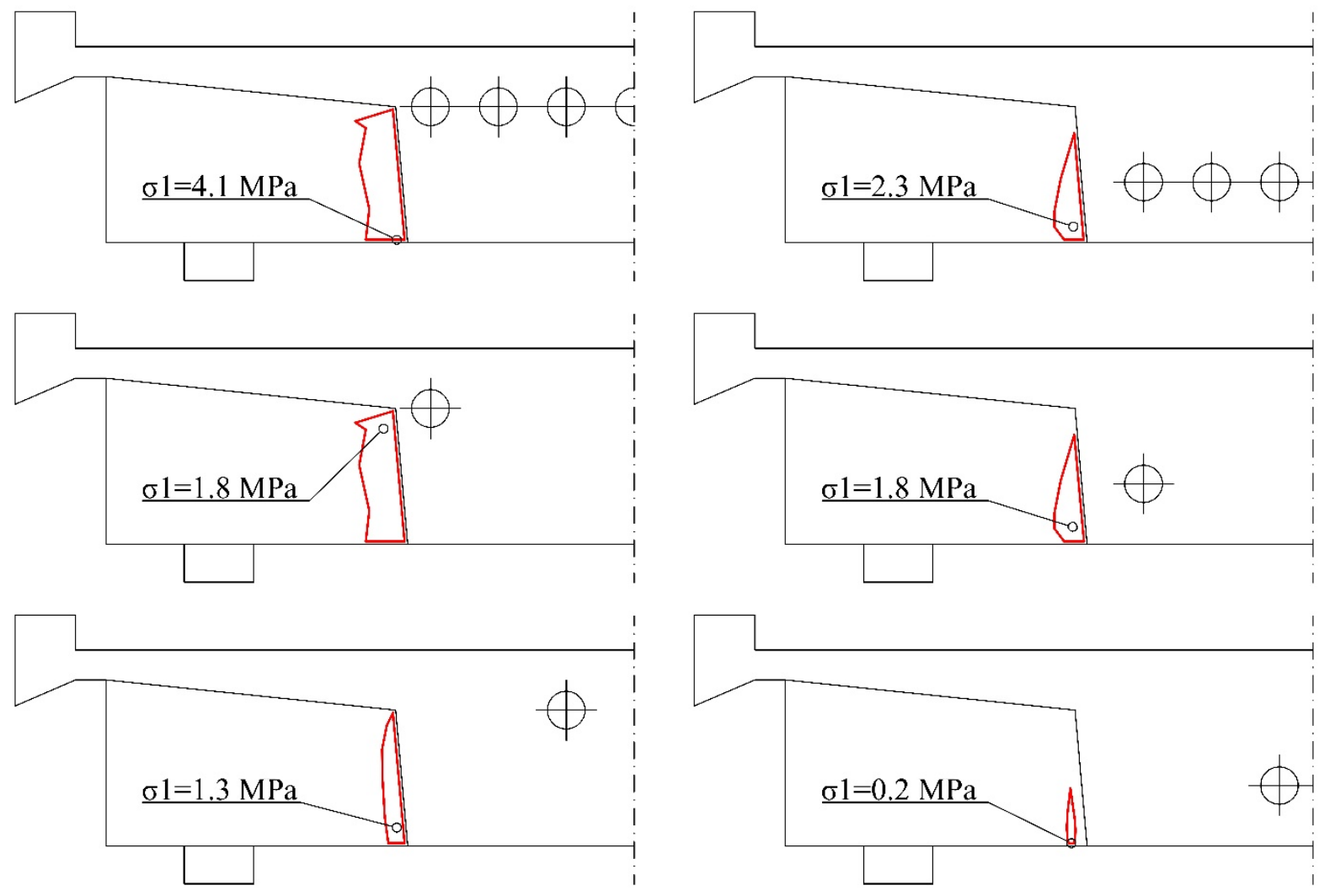

Figure 10 - Schematic tensile pattern by location of anchors, first case bridge

Compression due to post-tension force spreads out to the stresses in the end diaphragm at an angle of about $45^{\circ}$ and becomes narrower when transmitting towards the web of the girder. This presumably causes bursting stresses to the front surface of the end diaphragm, which is why the outer anchors cause higher tensile stresses. On the inner anchors, post-tension force cannot spread to the end diaphragm. Due to the post-tension force, the flanges of the girder also try to bend the end diaphragm.

\section{CONCLUSIONS}

The cracking on the end diaphragms of post-tensioned beam bridges is caused by the combination of loads, not by a single load. The tensile stresses caused by vertical loads, post-tension force and temperature difference occur in the same area at the corner of the end diaphragm and the main girder. The corner is a discontinuity area. Tensile force is mainly horizontal and it should be considered in the design of horizontal reinforcement on the front surface of the end diaphragm.

A linear model was sufficiently accurate to respond to the real structure despite the non-cracking behaviour. The cracks, which would have appeared according to the FE model, were in the same area as those detected in field surveys. The direction of the cracks would also have been the same. Presumably, a non-linear model would not have added more value to this study.

Adequate measures to reduce tensile stresses on the front surface of the end diaphragm were found, which would reduce cracking. Increasing the thickness of the end diaphragm does not have 
a significant reducing effect on cracking, whereas increasing the height of the end diaphragm and adding wedges on the corners of the end diaphragm and the main beam have a more beneficial effect. By placing the post-tension anchors more centrally, a reduction in cracking could be achieved. With small changes, it would be possible to achieve a clearly more functional structure.

For further research, the analysis of different case bridges is recommended, such as bridges with multiple main girders. This study does not include analysis of the post-cracking behaviour of the structure. In addition, the mechanism that leads to cracking could have been identified, so that cracking due to indirect support can be excluded. For that to be the case, structures should be analysed with a non-lineal model including reinforcement bars.

\section{ACKNOWLEDGEMENTS}

The research presented in this paper was financially supported by A-Insinöörit Oy and the Finnish Transport Agency.

\section{REFERENCES}

1. Fredriksson $\mathrm{H} \&$ Yhlen $\mathrm{H}$ : "FE-analysis of cracking in transversal support beams of concrete bridges". Master Thesis No. 2010:6, Chalmers University of Technology, Department of Civil and Environmental Engineering, Division of Structural Engineering, Göteborg, Sweden, 2010.

2. Kuusela M: "FEM analysis of causes of cracking in the end diaphragm of post-tensioned beam bridge". Report, Tampere University of Technology, Department of Civil Engineering, Tampere, Finland. 2016.

3. Finnish Transport Agency: "Liikenneviraston sillat". ("Bridges of the Finnish Transport Agency”.) 1.1.2016. Finnish Transport Agency, Helsinki, Finland, 2016. (In Finnish.)

4. LUSAS. Element reference manual. Version 15.2 Issue 1, 2016.

5. Vilonen H: "Soil-structure interaction of skewed integral abutment bridge". Report, Tampere University of Technology, Department of Civil Engineering, Tampere, Finland. 2007.

6. Mäntyranta L \& Laaksonen A: "Sillan ja maan yhteistoiminta, SIMA." ("Soil - Bridge Interaction".) Unpublished report, Tampere University of Technology, Department of Civil Engineering, Tampere, Finland. 2014.(In Finnish.)

7. SFS-EN-1992-1-1. (2004). Eurocode 2: Design of concrete structure. Part 1-1: General rules and rules for buildings. Brussels: CEN.

8. Leskelä M: "Betonirakenteiden suunnittelu ja mitoitus". ("Design of Concrete Structures".) Suomen Betoniyhdistys r.y. (Finnish Concrete Association), Helsinki, Finland, 2006. (In Finnish.) 
Nordic Concrete Research - Publ. No. NCR 60 - ISSUE 1 / 2019 - Article 6, pp. 89-104

\section{ANNEXES}

Table 1 - General information on field surveys, case bridges highlighted in blue/bold

\begin{tabular}{|c|c|c|c|c|c|c|c|c|c|c|c|c|c|c|}
\hline & 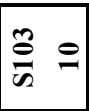 & & - & 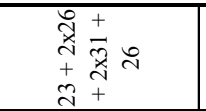 & $\ddot{n}$ & $n$ & $\stackrel{n}{\longrightarrow}$ & 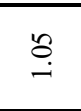 & ¿ & ஓें & $\stackrel{n}{m}$ & 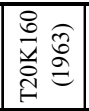 & 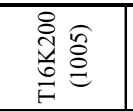 & $\star$ \\
\hline & $\bar{z}:$ & $\star$ & - & 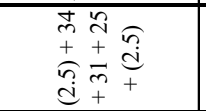 & $\tilde{i}$ & $\because$ & $\stackrel{n}{?}$ & $\stackrel{+}{r}$ & $\infty$ & $\hat{\sim}$ & & 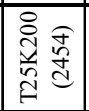 & 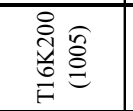 & $\tilde{0}$ \\
\hline & के $\stackrel{?}{\sim}$ & & - & $\begin{array}{l}\text { in } \\
\pm \\
\pm \\
\pm\end{array}$ & $\stackrel{n}{i}$ & & & & in & 㐫 & $\vec{m}$ & 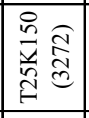 & 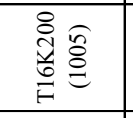 & $x$ \\
\hline & $\tilde{n}=$ & & - & 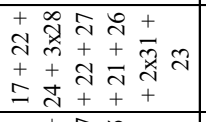 & $\ddot{n}$ & $\stackrel{n}{-}$ & $\stackrel{n}{n}$ & & $\stackrel{\circ}{1}$ & $\stackrel{i}{i}$ & $\stackrel{\circ}{\circ}$ & & & $\star$ \\
\hline & in & & - & 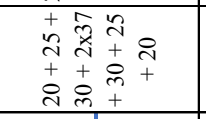 & $\because$ & $\stackrel{\leftrightarrow}{\rightarrow}$ & $\stackrel{\wp}{n}$ & $\exists$ & in & $\stackrel{\sim}{\Omega}$ & $\stackrel{\infty}{0}$ & 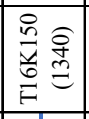 & 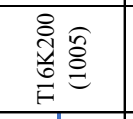 & 3 \\
\hline & 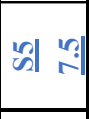 & & -1 & 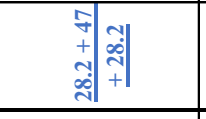 & $m$ & : & ?: & 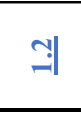 & 9 & (리 & $\stackrel{+}{i}$ & 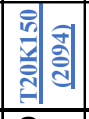 & 蒌: & $\stackrel{\square}{0}$ \\
\hline & 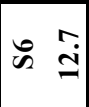 & & $\sim$ & 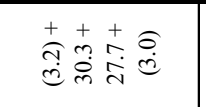 & $\stackrel{\infty}{-}$ & $\stackrel{n}{n}$ & $\stackrel{0}{-}$ & $n$ & $\begin{array}{l}0 \\
+ \\
0\end{array}$ & 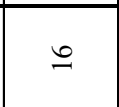 & & 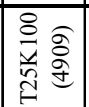 & 这 & กั \\
\hline & $\bar{n} \quad \pm$ & $\star A$ & $m$ & 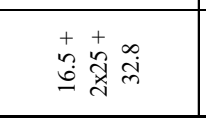 & $\stackrel{m}{i}$ & 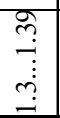 & $m$ & $\stackrel{n}{\longrightarrow}$ & $\begin{array}{l}0 \\
+ \\
+ \\
n \\
+ \\
\infty \\
\end{array}$ & 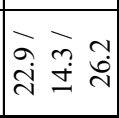 & & 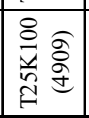 & 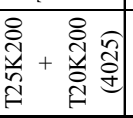 & $\overrightarrow{0}$ \\
\hline & $\frac{\pi}{\infty}+$ & $\star$ & - & 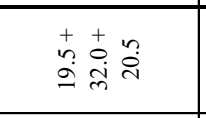 & $\stackrel{\Xi}{-}$ & $\stackrel{?}{3}$ & $\underset{i}{\stackrel{3}{+}}$ & לे. & in & $\stackrel{\infty}{\stackrel{\infty}{\subseteq}}$ & & 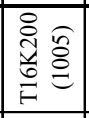 & 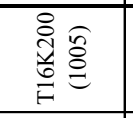 & $\tilde{0}$ \\
\hline & $\begin{array}{cc}0 & 0 \\
0 & 0 \\
\infty & 0\end{array}$ & & $\sim$ & 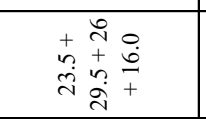 & 9 & $\stackrel{?}{9}$ & $\stackrel{\text { fo }}{-}$ & $\stackrel{\cong}{=}$ & $\begin{array}{l}0 \\
+ \\
0\end{array}$ & مْ & $\stackrel{?}{F}$ & 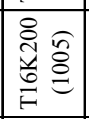 & 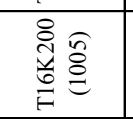 & $\star$ \\
\hline & $\begin{array}{ll}\hat{N} & \infty \\
\tilde{\infty} & \infty\end{array}$ & & - & 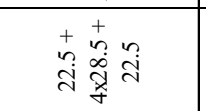 & $\ddot{n}$ & $\stackrel{?}{3}$ & $\stackrel{?}{?}$ & - & $=$ & $\stackrel{\nabla}{\oplus}$ & $\vec{i}$ & 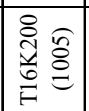 & 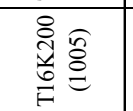 & $\because$ \\
\hline & $\begin{array}{ll}\tilde{z} & n \\
\infty & 0 \\
\end{array}$ & $\star$ & 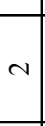 & 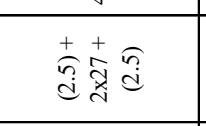 & $\stackrel{\infty}{-}$ & $\stackrel{?}{?}$ & $\begin{array}{l}\vec{a} \\
i \\
i \\
i \\
i\end{array}$ & $\begin{array}{l}n \\
n \\
n \\
0\end{array}$ & $\begin{array}{l}0 \\
+ \\
+ \\
0\end{array}$ & iे & $\stackrel{\infty}{+}$ & 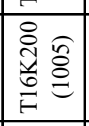 & 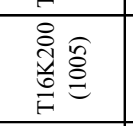 & 3 \\
\hline & $\frac{\infty}{\vec{n}}=$ & & $N$ & 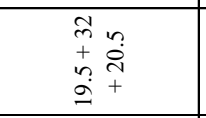 & $\stackrel{\circ}{-}$ & $\stackrel{0}{-}$ & $\stackrel{0}{-}$ & - & $\stackrel{-}{+}$ & $\because$ & $\stackrel{+}{+}$ & 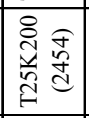 & 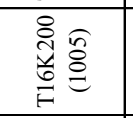 & $\star$ \\
\hline & $\underset{n}{ \pm}=$ & & $N$ & 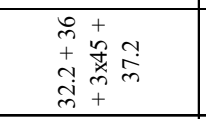 & $\stackrel{\text { I }}{-}$ & $\vec{i}$ & $\vec{i}$ & - & $\begin{array}{l}\infty \\
+ \\
\infty\end{array}$ & $\hat{\vec{i}}$ & $\stackrel{\leftrightarrow}{\dot{r}}$ & 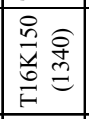 & 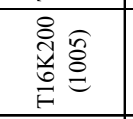 & $\begin{array}{c}n \\
0 \\
\vdots \\
\vdots \\
0 \\
0\end{array}$ \\
\hline & $\begin{array}{l}4 \\
\vec{n} \\
\vec{n}\end{array}$ & & $N$ & 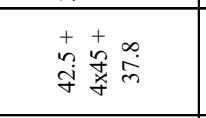 & $\stackrel{\sim}{乛}$ & $\vec{i}$ & $\vec{i}$ & - & $\begin{array}{l}\infty \\
+ \\
\infty\end{array}$ & $\stackrel{\infty}{\dot{i}}$ & $\stackrel{\infty}{i}$ & 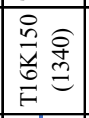 & 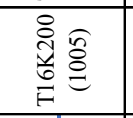 & $\begin{array}{c}n \\
n \\
\vdots \\
\vdots \\
0 \\
0\end{array}$ \\
\hline & $\begin{array}{ll}\infty \\
\vdots \\
\vdots\end{array}$ & $\star 1$ & -1 & 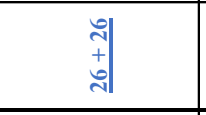 & लैं & $\stackrel{3}{=}$ & m: & $\stackrel{0}{=}$ & -1 & $\stackrel{0}{=0}$ & लें। & 㝬: & 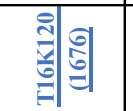 & ¿े| \\
\hline & 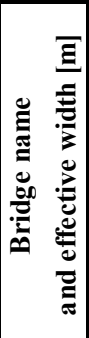 & 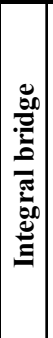 & 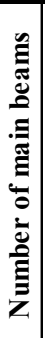 & 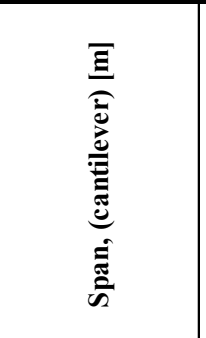 & 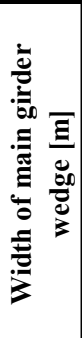 & 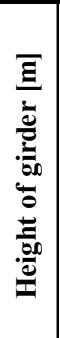 & 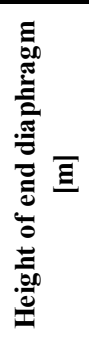 & 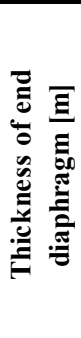 & 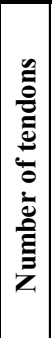 & 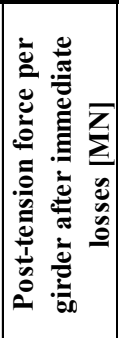 & 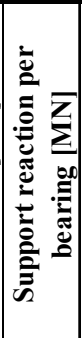 & 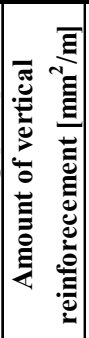 & 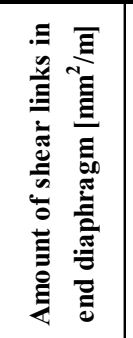 & 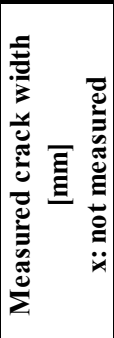 \\
\hline
\end{tabular}


Nordic Concrete Research - Publ. No. NCR 60 - ISSUE 1 / 2019 - Article 6, pp. 89-104

Table 2 - Used post-tension force, restrain forces and support reactions

\begin{tabular}{|c|c|c|c|c|c|}
\hline Post-tension force, after immediate losses & $\vec{\Xi}$ & 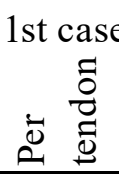 & 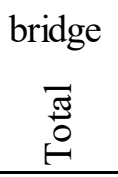 & 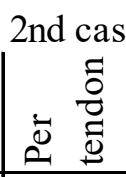 & $\begin{array}{c}\text { e bridge } \\
\overrightarrow{0} \\
0 \\
0\end{array}$ \\
\hline Longitudinal post-tension force & $\mathrm{MN}$ & 2.7 & 35.2 & 2.6 & 18.3 \\
\hline Equivalent load at anchor, upper tendons & $\mathrm{kN}$ & -87.4 & -611.8 & -330.3 & -2312.1 \\
\hline Equivalent load at anchor, lower tendons & $\mathrm{kN}$ & -1.3 & -7.7 & & \\
\hline Equivalent line load, upper tendons & $\mathrm{kN} / \mathrm{m}$ & 12.5 & 87.8 & 29.0 & 203.2 \\
\hline Equivalent line load, lower tendons & $\mathrm{kN} / \mathrm{m}$ & 8.0 & 47.9 & & \\
\hline
\end{tabular}

\begin{tabular}{|c|c|c|c|}
\hline Support reaction per be aring & 节 & 1st case bridge & 2nd case bridge \\
\hline Self-weight of structures & $\mathrm{kN}$ & 630.4 & 939.2 \\
\hline Deadload of surface structures etc. & $\mathrm{kN}$ & 104.2 & 148.9 \\
\hline Upper tendons & $\mathrm{kN}$ & 18.5 & 93.1 \\
\hline Lower tendons & $\mathrm{kN}$ & 74.5 & \\
\hline Traffic load, total & $\mathrm{kN}$ & 924.0 & 876.7 \\
\hline
\end{tabular}

